\section{Technology enables greater working flexibility}

UK cloud practice management software company Dentally commissioned a survey to look back at the past 12 months to understand the challenges and mood of the market following the COVID-19 pandemic.

The 'State of Dentistry 2021' report has produced findings that have reflected both the shift in opinions towards the industry itself and the role that technology has adopted over this period.

As we emerge from a further lockdown, it is clear to see that the demand for dentistry is greater than ever. We now have a 'new normal' for dentistry which has directly impacted standards for ease of use in technology. With $15 \%$ more practitioners than the previous year finding they spent too much time on NHS administration, it is an important takeaway that software leaders should be reactive to ongoing practice frustrations and seize the chance to create ever more powerful, yet user-friendly solutions.

While in 2020 we've seen a reduction in dentists agreeing that technology has made practice management easier, $27 \%$ less than the previous year, the demands of the pandemic increased the need for remote working allowing administrative tasks to be completed away from the office. With $78 \%$ of those surveyed sharing the optimism that technology allows them to work more flexibly, this wave of hope introduces new opportunities for the year ahead to rectify the work-life imbalance that many dentists have expressed.

Amongst the changes witnessed over the past 12 months, from the patient's journey to the way dental practices operate day to day, it is apparent that delivering excellent patient care remains an industry-wide priority. It is now up to the key opinion leaders to react to these changes and develop solutions in line with the growing needs of practice owners and their patients.

To read the full White Paper report: 'The State of Dentistry' visit https://info. dentally.co/smile-2021-0.

https://dentally.co.

\section{Affordable disinfection made easy}

Are you looking for a surface cleaner that effectively cleans even the toughest to reach spots of your practice?

AIRGENE CE Airborne Surface Disinfectant from

Eschmann is a smart way to help guarantee that indoor surfaces are properly disinfected. The unique one-shot technology forms a cloud of the product that covers an area of $40 \mathrm{~m} 3$ in under one hour, destroying $99.99 \%$ of bacteria and viruses, including coronavirus, and neutralising odours caused by the decomposition of surface bacteria.

AIRGENE CE Airborne Surface Disinfectant is available to purchase on the Eschmann website as a single unit and in cases of 12 .

To find out more, contact Eschmann today.

For more information on the highly effective and affordable range of infection control products from Eschmann, visit www.eschmann.co.uk or call 01903 875787.

\section{Exceptional cleaning performance}

Manufacturer W\&H is proud to introduce the new Teon thermal washer disinfector, offering exceptional performance for highly efficient cleaning and reprocessing of dental instruments.

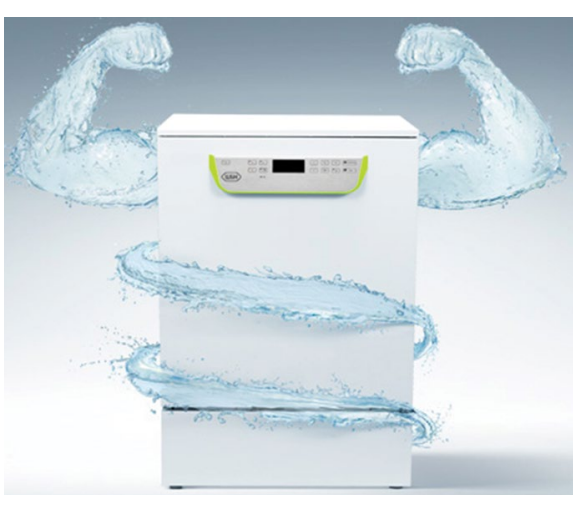

With its high-capacity chamber, the Teon is optimised to accommodate a larger throughput of instruments, and can easily integrate into your decontamination workflow, given its user-friendly interface and dedicated custom programmes.

To promote maximum user confidence, the Teon also comes with a range of additional safety features. This includes an integrated spray arm monitoring system, a speed variable pump, an advanced filter system, and an automatic door lock.

Discover how to enhance the costefficiency of dental decontamination with Teon.

To find out more visit www.wh.com/en_uk, call 01727874990 or email office.uk@wh.com.

\section{Ensuring compliance and quality assurance}

Following the UK's exit from the European Union, the Medicines and Healthcare products Regulatory Agency (MHRA) is now the UK's standalone medicines and medical device regulator. This means that any medical devices imported to and sold within the UK must comply and be registered with the MHRA.

Regulatory compliance and quality assurance have always been priorities for the Straumann Group. As such, it is now confirmed that Straumann UK has been appointed as the UK Responsible Person and will act on behalf of all Straumann Group companies in this capacity.

Straumann Group are pleased to have completed all the necessary registrations for its products, including Straumann, Anthogyr, Neodent, ClearCorrect, Createch, Medentika, Valoc and Dental Wings.

For more information on the products and services available from the Straumann Group, visit https://www.straumann.com/group/en/home.html/. 